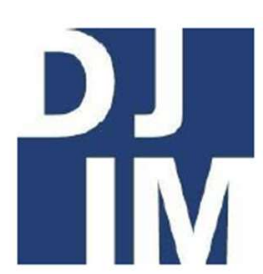

Volume 16

Spring

2021

ojs.library.dal.ca/djim

\title{
Reflections on the Public Library System in Canada: Inclusivity, Race and Power
}

\author{
Grace Bourret
}

School of Information Management, Faculty of Management, Dalhousie University

\begin{abstract}
Public libraries as an institution are of the upmost importance to Canadian society as individuals from a variety of socioeconomic and cultural backgrounds rely upon these spaces to gain access to information, education, and recreational activities. For this reason, these institutions strive to be inclusive and welcoming spaces. However, they are not always successful in these endeavours. The following paper highlights the ways in which Canadian libraries promote a homogenous culture of whiteness. Although this subject has been discussed in the American context, this paper situates Canada within this scholarship through investigating the makeup of Canadian libraries, the treatment of library patrons, and the documented experiences of racially marginalized staff. Based on these findings, this paper highlights scholarly and practitioner recommendations while also advocating for further research on this topic within the Canadian field of Library and Information Sciences (LIS).
\end{abstract}




\section{Introduction}

Public libraries are places where individuals from a variety of socio-economic and cultural backgrounds come together in one space. Whether these individuals are there to find a peaceful spot to think, find shelter for the day, use technological devices, or simply browse through a collection of books, the modern public library is a multifaceted space designed to meet the needs of Canadian society. In many ways this institution strives to be an inclusive and welcoming space (Beaudry et al., 2014; Working Together Project, 2008). However, there are areas where libraries fall short of these ideals. The public library can often inadvertently be a harmful and oppressive institution within Canadian and North American society at large as they continue to promote a homogeneous culture of whiteness (Brook et al., 2015). Although this subject has been discussed indepth in the American context (Espinal et al., 2018; Santamaria, 2020; Brook et al., 2015), there remains a lack of discussion in Canada (Schmidt, 2019). The following paper situates Canada within scholarship through investigating the makeup of Canadian libraries, the treatment of library patrons, and the documented experiences of racially marginalized staff. In addition, this paper examines the inclusivity initiatives already in place, and concludes by highlighting scholarly and practitioner recommendations for better inclusivity in the future. Until these systems are confronted and dismantled, the library will fail to be a truly safe space for all users.

\section{The Public Library and its Initiatives}

Within Canadian society, the public library has diverse, complex and everchanging purposes. As Summers and Buchanan (2018) note, the library is a "trusted space where people can come together to access, share and create cultural resources and materials" (p. 286). Indeed, on a fundamental level, the library provides individuals with information through the use of books, technology, music, magazines, and many other materials. Users can even create works of their own through musical instruments and computer technology available at the library. The public library also provides community members with a public meeting place where anyone can participate in activities both formally and informally (Aabø et al, 2010). For many individuals, library visits are a part of a daily ritual which facilitates social contact and connection with other community members (May \& Black, 2010). Additionally, several libraries have also embraced community-led initiatives where library programming and services are based completely on the needs of the community (Bethune, 2018; Williment, 2020). Far beyond simply borrowing books, the public library serves a vital role within Canadian society. 
Consequently, the library has very diverse users who come from a wide array of cultural and socio-economic backgrounds. As Williment (2020) notes, the library is traditionally home to the patronage of the middle-class. Yet, at the same time, public libraries are also home to "disadvantaged and displaced populations" (Ettarh, 2019, para. 6) such as unhoused individuals, people released from federal institutions, mentally ill individuals, youth at risk, and people living in poverty (Williment, 2020). The library also sees many newcomers because libraries are among the first places that immigrants and refugees visit in effort to "develop trust and see how they fit into the community" (May \& Black, 2010, p. 19). Within these distinct community groups, there are also children, teens, youth, adults and elderly folks of all backgrounds who find use in the public library system. Across North America, the library not only offers a wide array of services, but it also draws in a diverse group of visitors.

With this in mind, the public library has made strides to make their spaces as welcoming and inclusive as possible. This is evident in Nova Scotia's Public Libraries' (n.d) “Strategic Plan 2017-2021", which states that the library should exist as a "a resource for everyone" (p. 4) and its main goal is to obtain social equality through "ensuring access for all individuals" (p. 10). The Halifax Public Libraries (n.d) also state the library should "mirror and deeply respect the diversity of our many communities" (pg. 15). Similarly, one of the most highly rated core competencies for librarians is the ability to "create a welcoming, useful library environment to encourage use and strengthen support of the library community" (Helmick \& Swigger, 2006, p. 63). In essence, it is the library's highest priority to make the space welcoming to all patrons and users.

Public libraries in Canada did not simply set these goals and make blanket statements. Instead, they actively attempted to attain these objectives. For example, Lam (2020) mentions when building the Halifax Central Library, FBM Architectures and Schmidt Hammer Lassen actively sought out recent immigrants for consultations when building the library in effort to make the space as welcoming and accessible as possible. This idea was largely successful, as after receiving feedback, the community had the opportunity to shape the design of English as Second Language (ESL) classrooms which are designed to and positioned in the building to provide comfort and privacy for individuals learning a new language (Lam, 2020). This accessibility was also embraced in other areas, as the library purposely made the washrooms large enough for library patrons to have baths to wash themselves if needed (Lam, 2020). Through the library's architecture and building plans, Halifax is actively trying to make their libraries a safe and accessible space for their patrons. 
Beyond Halifax, these initiatives have also occurred across Canada through the implementation of the Working Together Project which was created by Human Resources Development Canada (Working Together Project, 2008). The Working Together Project began in the early 2000s and involved Vancouver, Regina, Toronto, and Halifax Public Libraries in attempt to better include all members of society and identify areas in which the library can improve (Beaudry et al., 2014). The Working Together Project Toolkits describes itself as a "...community development approach [that] encourages and promotes philosophies, strategies and empathies that build and strengthen relationships between socially excluded community members and the libraries" (British Columbia Libraries Association, 2015, para. 1). Through the creation and implementation of this program, the Vancouver, Regina, Toronto, and Halifax Public Libraries began to prioritize the needs of excluded and marginalized communities (Beaudry et al., 2014). To accommodate and serve the diverse and everchanging patronage of the library, Canadian public libraries have made deliberate actions to make the library a welcoming space for all.

This is only further emphasized through the code of ethics released by the Canadian Federation of Library Associations-Federation Canadienne des associations de bibliothèque (CFLA-FCAB), a national federation dedicated to library excellence in Canada (Canadian Federation of Library Association, n.d). Significantly, in this code of ethics (Garcia-Febo et al., 2018), the CFLA-FCAB rejects the denial and restriction of access to information based on one's "age, citizenship, political belief, physical or mental ability, gender identity, heritage, education, income, immigration and asylum-seeking status, marital status, origin, race, religion or sexual orientation" (Garcia-Febo et al., 2018, para. 9). With these measures in place, Canadian public libraries have made deliberate initiatives to promote inclusivity and denounce discrimination on both a local and national level. However, these initiatives are still not enough.

\section{The Public Library and Whiteness}

Although the public library advocates for inclusivity and diversity, the institution itself remains extremely homogenous. Many scholars and professionals have indicated that the vast majority of librarians are white (Bourg, 2014; Blackburn, 2015; Hathcock, 2015; Schmidt, 2019). Within Canada, $88 \%$ of librarians are white and the number of Indigenous librarians has stayed at less than $1 \%$ for the past ten years (Schmidt, 2019). Additionally, Brook et al. (2015) argues the profession has been well aware of this overrepresentation of white staff for several decades, as Black, Indigenous and People of Colour (BIPOC) librarians have expressed 
concerns about the lack of career opportunities and disproportionate staffing of BIPOC individuals (Matthews, 2020). Despite claims of inclusivity, the library as an institution itself remains to be overwhelmingly white.

Not only is the public library's workforce predominately white, but there is also a majority of white women in the field. This is significant as it holds historical precedence as white women were encouraged to enter into the field of librarianship as they were "considered unthreatening, safe and nonrevolutionary" (Schlesselman-Tarango, 2017, p. 6). Although this claim is not necessarily true in a contemporary context, white femininity can still be called upon within the library to hide or undermine the "violence of whiteness and white supremacy within the library" (SchlesselmanTarango, 2017, p. 2). Therefore, the library not only has a disproportionately white staff, but the feminization of this profession can also be used as a tool to present the library as a neutral and non-threatening space while remaining a fundamentally white institution.

However, the whiteness of the public library extends far beyond just the race of the staff themselves. Whiteness is not only a racial category, but it is a "complete system of exclusion based on hegemony" (Hathcock, 2015, para. 3). Amber Matthews (2020) asserts the dominance of whiteness is maintained within the library through "unacknowledged norms, values and structures" (p. 5) that all have ingrained notions of race neutrality. This takes many forms, as even the concept of the library as a silent space is one that was constructed and informed by white European precedents, and it has been proven that the majority of non-white patrons work better in hybrid social spaces (Beilin, 2017).

Furthermore, the library's structure itself is also coded as a white space. As Beilin (2017) notes, libraries are often designed in certain styles which deliberately evoke European precedents to place these institutions within a Western tradition that links the library with other structures that share a similar style, such as courts and government buildings (Beilin, 2017). Yet, as Santamaria (2020) argues, even if a library is not traditional in its architecture, the way a library looks is still a statement of its values and ways of thinking. Therefore, the size and often brutalist architecture of many Canadian libraries still demands the attention and power in a way that follows Western traditions. Through its staff, norms, and physicality, whiteness remains promoted and practiced within the public library.

\section{The Public Library and its Patrons}

This lack of diversity has a serious impact on patrons as it dissuades individuals from feeling comfortable and welcomed within the library. 
Galvan (2015) notes that libraries are often a source of anxiety for individuals of a nondominant culture as they are not only learning how to use library resources but are also "navigating culture" (para. 8). For this reason, marginalized community members often prefer to interact with staff members who have a shared background or common language as these individuals are more comforting and familiar (Brook et al, 2015). A lack of diversity amongst library staff often prevents patrons from seeking help or even using the library at all (Brook et al, 2015). Despite the library's claims and initiatives geared towards fostering diversity, the whiteness of the institution itself creates barriers for patrons.

In particular, this whiteness is very detrimental for teenage patrons and youth. As Amber Matthews notes, racialized youth represent over a quarter of the youth population in Canada, which makes this demographic a significant population in the library. However, individuals in this demographic rarely sees themselves or their culture reflected within library programs or collections as librarians are often unaware of social or cultural preferences (Matthews, 2020). For example, although Toronto Public Library has continuously created strategies for youth services, they do not account for racialized youth or attempt to improve these services (Matthews, 2020). In complete opposition to the public library's goal, the library's whiteness causes racialized youth to look outside of the libraries for cultural information because their needs are often not met in these spaces (Matthews, 2020). Due to the library's lack of diversity, many youths are unable to find the library useful at all.

Additionally, the library's whiteness impacts the quality of service itself. Reference librarians often take an apolitical stance toward race and claim that their services are colour blind (Brook et al, 2015). However, despite these claims marginalized communities often do not receive the same quality of service. This was specifically outlined in Shachaf \& Horowitz's 2006 study which illustrated how virtual reference services provided to African Americans and Arabs were lower in the quality of service compared to that provided to Hispanic, Jewish and Caucasian patrons, as librarians sent shorter responses to these individuals and took longer to reply. These same findings were emphasized by Brook et al. (2015), as the authors note that marginalized communities do not receive the same quality of reference services as white patrons because white librarians tend to be less approachable to marginalized patrons and lack knowledge and empathy regarding marginalized individuals' experiences. In these instances, the whiteness of the library and library staff directly impacts the experience and quality of service provided to non-white or marginalized patrons. 
Within Canada, there are explicit cases where the public library's whiteness directly hurts patrons of the library. This was particularly evident at the Winnipeg Millennium Library, as on February 25, 2019, the downtown location instituted new security measures in response to a series of incidents within the library (Selman \& Curnow, 2019). These security measures involved patrons lining up and going through "airport like security to enter the library," (Selman \& Curnow, 2019, p. 2) where security guards checked their bags and forced patrons to have their bodies scanned by metal detectors. Any items which were deemed to be against library policies were taken from them. More often than not, these items were mundane objects such as knitting needles, bike repair tools, scissors, and nail clippers (Selman \& Curnow, 2019). Security guards also had the power to turn individuals away while other individuals decided to leave themselves as the visit was judged not worth the entrance process. Whether this was done purposefully or not, these measures ultimately targeted marginalized patrons while benefiting the library's white patrons.

This increased level of security deliberately made racialized patrons of the library unsafe in an effort to "protect" individuals who are often unimpacted by these systems. Research has shown that an increased level security does not lead to less crime, but it results in more individuals who are most likely from BIPOC communities to be labelled as criminals or deviant, which in turn causes them to be brought in contact with criminal punishment institutions (Selman \& Curnow, 2019). Additionally, as Selman and Curnow (2019) highlight, the Winnipeg Millennium Library is a space where patrons are likely to be Indigenous or newcomers so this level of security would impact a huge number of the library's patronage. This was evident as racial profiling was witnessed first-hand. One patron in particular stated that the "security guards [were] much more thorough with people who [looked] a certain way," speaking particularly about race (Caruk, 2020, para.19). Individuals who are white or white passing would often remain unaffected by these security measures, whereas BIPOC individuals are forced to endure security measures that can put them in unsafe situations and can be emotionally- triggering.

Beyond race, these measures were also extremely dangerous for mentally ill and unhoused individuals who are also a significant population within the library (Selman \& Curnow, 2019). This is highlighted by the Association of Specialized and Cooperative Library Agencies (2010), as they assert that while individuals with mental illness are more likely to be victims of violence than the perpetrators, they are often still viewed as threats to society. This label ultimately causes security to be more forceful 
and aggressive toward these individuals. Additionally, due to the increased level of security, unhoused individuals could also be rejected access to the library which causes "marginalized patrons to be pushed out into the cold" (Selman \& Curnow, 2019, p. 2) in a city with frigid winters that put their life at risk. Despite the library's claim to become a safe and inclusive space, they still implement discriminatory and harmful policies that makes the public library an unsafe space for countless individuals. Unfortunately, the Winnipeg Millennium Library is only one instance of this.

\section{The Public Library and its Staff}

Beyond the impact on patrons, the whiteness of the library also has a significant and detrimental impact on the staff themselves. BIPOC staff members often feel as though they need to conform to euro-centric norms due to the overwhelming whiteness of the institution which can be a profound emotional burden. As Watson (2017) notes, libraries and librarians often expect their leaders to amplify the dominant culture and ask their leadership candidates to "perform whiteness" (p. 155). This is a huge demand that causes a lot of emotional labour in a profession that already forces BIPOC librarians to fight for credibility and authority within their workplace (Watson, 2017). In addition to this, the need to conform also encourages women of colour to become "complicit in the very structures of their oppression" (Watson, 2017, p.157) which is another heavy burden that these individuals need to endure to succeed. This conformity is an emotional and harmful barrier which libraries perpetuate.

The library's harm toward their own staff can also be seen in more explicit instances such as blatant forms of discrimination within libraries. Looking specifically at dress codes, Macias (2017) notes that the standard grooming and dress code policies in libraries often prioritize Western standards of dress and do not account for people of colour. In particularly, dress codes often ban "unnatural or distracting hairstyles [and]...unkempt hair or clothing" (Macias, 2017, p. 114) and are typically created by a predominantly white senior staff members. Through these standards, the library creates a climate that upholds white standards of appearance which inflicts barriers for BIPOC staff members that can hinder their professional growth (Macias, 2017). Within LIS environments, as Macias (2017) argues, "white is standard and deviations are off-putting at best and criminal at worst" (p. 116). Even the library's dress codes targets and discriminates against BIPOC staff members, a microaggression that highlights the deeper issues within the institution.

In terms of staff members, BIPOC individuals have continuously reported they find it to be immensely stressful and oppressive to work within these institutions. Twenty per cent of LIS 
professionals in the United States left the profession due to racial trauma in the workplace (Schmidt, 2019). This occurs because LIS institutions often look at diversity "as an equation to be solved or a check box to be ticked" while ignoring "the lived experience of those who work in our institutions" (Schmidt, 2019, p. 4). Without the institutions changing, attempts to hire diverse staff members often results in the "tokenization, alienation, doubt, undervaluation, prejudice and hostility of or towards these individuals" (Brook et al, 2015, p. 263). Watson (2017) argues that librarians of colour encounter microaggressions, other types of stereotyping, and silencing tactics on a daily basis, which ultimately hinders these individuals' motivation and capability of working at the same level of their white coworkers. Due to this process an increasingly homogenous workforce is created, especially in regard to those in leadership positions. As libraries are hiring BIPOC individuals before dismantling the institution's racism itself, the library is often a harmful and unsafe space for the staff members.

This was particularly evident within the Thunder Bay Public Library, which was discussed in a Canadaland: Thunder Bay podcast produced by Ryan McMahon (2020). In this podcast, McMahon (2020) draws attention to the library's efforts to diversify their library, in which the Thunder Bay Public Library created two job postings for individuals that did not need to have work experience as a librarian, but instead were able to provide the lived experience of being an Indigenous person who could assist in providing a better reflection of Indigenous culture, values, art, and literature. Although this initiative may have been well-intended, it resulted in discrimination and a lack of support and resources for the staff. Staff member Samantha Bird said that within her first week, her colleagues confronted her as a group, telling her that it was hard for them to view her as a peer and that she did not deserve to be there, even though she was hired for the specific skill sets she possesses (McMahon, 2020). In addition, Bird noted that she faced daily stress, microaggressions, was held to a higher standard, and had to prove herself more than other people (McMahon, 2020). On an institutional level, Canadian public libraries can still be an oppressive, which poses many barriers for marginalized staff members.

\section{Considerations and}

\section{Recommendations}

Clearly, there is no quick fix to this ongoing systemic problem. Both staff and visitors of the public library have been drawing attention to and actively working toward dismantling these problems for several years now. However, certain measures should be highlighted which both scholars and practitioners of the field have been advocating for several years now. 
Particularly, as Blackburn (2015) indicates, all public library staff should partake in cultural competency training that specifically includes awareness of whiteness in the library, of privilege, and how this whiteness makes certain things available to some and not others. Through effective cultural competency, as Blackburn (2015) argues, information can truly become accessible, and the library can become a safe space for all patrons and staff. In addition to this, libraries across Canada must continue to embrace community-led approaches as highlighted in the Working Together Project Toolkit. Through community-led approaches, library workers can work with community groups to meet their needs and make the library a more welcoming space. Without collaboration, inclusivity can never be achieved.

Diverse hiring initiatives are also necessary but, as indicated previously, structural change must occur as well. Dali and Caidi (2017) propose that one way to make the field more diverse is to provide LIS students with more diverse and inclusive training while they are in their programs because it was found that students felt more comfortable discussing diversity in theoretical terms rather than practicing these methods themselves. The integration of handson diversity training would be beneficial so students can enter the field prepared and trained rather than being inexperienced and risk creating an unsafe or unwelcoming environment for someone as a librarian. Significantly, these programs should not only be catered to white students but the readings, methods of teaching, approach and staff should also be diverse. To make the LIS profession more inclusive, it is necessary that the programs and methods of teaching in LIS programs are also inclusive and diverse.

Finally, it is also important to recognize that making these changes is not a linear task. As Schmidt (2019) notes, this means accepting that there is always more research to be done, more to learn, a new perspective to see and more room for active listening to promote understanding. Most significantly, it is not the job of marginalized individuals to bring these issues to the forefront, exist as resources for white librarians, or solve these problems alone. Instead, white library staff must rise to the occasion and truly exist as allies and agents of change in the library.

\section{Conclusion}

Public libraries are undeniably a beneficial aspect of our modern society. Every day, Canadian public libraries distribute freely information in countless ways to thousands of people across the country. However, this does not mean there is not a need for some dramatic improvements. Although it is the library's objective to be welcoming, inclusive, and equitable to all patrons, there are many factors that prevent this 
from happening. Primarily, the library as an institution continues to promote a culture of whiteness through its values, policies, and staff. This is detrimental to patrons as it impacts their quality of service, experience, access to relevant materials, and even makes the space itself unsafe and unwelcoming. Additionally, the institution's whiteness imposes harm and barriers as it promotes conformity and causes patrons and staff to endure racism on a daily basis. Until the library attempts to be inclusive at an institutional and structural level, it will continue to embody homogenous values of whiteness, and fail to be a truly inclusive and welcoming space to all. These barriers and lack of effective action are preventing the library from reaching its full potential within society.

\section{References}

Aabø, S., Audunson, R., \& Vårheim, A. (2010).

How do public libraries function as meeting places? Library \& Information Science Research, 32(1), 16-26. https://doi.org/10.1016/j.lisr.2009.07.0 08

Association of Specialized and Cooperative Library Agencies. (2010). People with mental health issues: What you need to know.

http://www.ala.org/asgcla/sites/ala.org .asgcla/files/content/asclaprotools/acce ssibilitytipsheets/tipsheets/7-

Mental_IIIIness.pdf

Beaudry, G., Bjornson, P., Carroll, M., \& Demers, P., (2014). The future now:

Canada'sibraries, archives, and public memory. Royal Society of Canada.

Beilin, I. (2017). The academic research library's White past and present. In F. Schlesselman-Tarango (Eds.), Topographies of Whiteness: Mapping Whiteness in Library and Information Science. (pp. 79-100.) Library Juice Press.

Bethune, B. (2018). How public libraries are reinventing themselves for the $21^{\text {st }}$ century. Maclean's. https://www.macleans.ca/society/howpublic-libraries-are-reinventingthemselves-for-the-21st-century/

Blackburn, F. (2015). The intersection between cultural competency and whiteness in libraries. In the Library with the Lead Pipe.

http://www.inthelibrarywiththeleadpip e.org/2015/culturalcompetence/

Bourg, C. (2014). The Unbearable whiteness of librarianship. Feral Librarian. https://chrisbourg.wordpress.com/2014 /03/03/the-unbearable-whiteness-oflibrarianship/ 
British Columbia Library Association. (2015).

Working Together Project.

https://bclaconnect.ca/professional-

development/the-working-together-

project-toolkit/

Brook, F., Ellenwood, D., \& Lazzaro, A. E. (2015).

In pursuit of antiracist social justice:

Denaturalizing whiteness in the

academic library. Library Trends, 64(2),

246-284.

http://dx.doi.org.ezproxy.library.dal.ca/

10.1353/lib.2015.0048

Canadian Federation of Library Association.

(n.d). About. Canadian Federation of

Library Association. https://cfla-

fcab.ca/en/about/

Caruk, Holly. (2019, March 14). 'It's a dark stain

on our city': Millennium Library lovers

meet with staff to discuss security

measures. CBC News.

https://www.cbc.ca/news/canada/mani

toba/library-patrons-meeting-concerns-

security-1.5057661

Dali, K. \& Caidi, N. (2017). "Diversity by design."

The Library Quarterly, 87 (2), 88-98.

https://doi.org/10.1086/690735

Espinal, I., Sutherland, T., \& Roh, C. (2018). A

holistic approach for inclusive

librarianship: Decentering whiteness in

our profession. Library Trends, 67(1),
147-162.

https://doi.org/10/1353/lib.2018.0030

Ettarh, F. (2019, January 10). Vocational awe and librarianship: The lies we tell ourselves. In The Library With the Lead Pipe.

http://www.inthelibrarywiththeleadpip e.org/2018/vocational-awe/

Garcia-Febo, L., Hustad, A., Rösch, H., Sturges, P., \& Vallotton, A. (2018). CFLA-FCAB Code of Ethics. Canadian Federation of Library Association. http://cflafcab.ca/en/guidelines-and-positionpapers/code-of-ethics/

Galvan, Angela. (2015, June 3). Soliciting performance, hiding bias: Whiteness and librarianship. In The Library with the Lead Pipe.

http://www.inthelibrarywiththeleadpip e.org/2015/soliciting-performancehiding-bias-whiteness-andlibrarianship/

Halifax Public Libraries. (n.d). Strategic Plan: 2017-2021. Halifax Public Libraries. https://d4804za1f1gw.cloudfront.net/w pcontent/uploads/sites/50/2018/02/301 32648/HfxPublicLibraries-StratPlan2017-web.pdf

Hathcock, A. (2015, October 7). White librarianship in blackface: Diversity 
initiatives in LIS. In The Library With The Lead Pipe.

http://www.inthelibrarywiththeleadpip e.org/2015/lis-diversity/

Helmick, C., \& Swigger, K. (2006). Core competencies of library practitioners. Public Libraries, 45(2), 54-69.

Hines, Samantha. (2019). "Leadership development for academic librarians:

Maintaining the status quo?". Canadian Journal of Academic Librarianship 4, 1-19. https://doi.org/10.33137/cjalrcbu.v4.29311

Lam, E. (2020). The new public library. The Canadian Architect, 65(1), 4.

McMahon, R. (Executive Producer). (2018present). "It happens because you're Indigenous." [Audio podcast].

Canadaland: Thunder Bay. https://www.canadaland.com/podcast/i t- happens-because-youreindigenous/

Macias, J. (2017) "Looking the part". In F. Schlesselman-Tarango (Eds.), Topographies of Whiteness: Mapping Whiteness in Library and Information Science. (pp. 113-120). Library Juice Press.
Matthews, A. (2020). Racialized youth in the public library: Systemic racism through a critical theory lens. Partnership, 15(1), $1-17$.

May, F., \& Black, F. (2010). The life of the space: Evidence from Nova Scotia public libraries. Evidence Based Library and Information Practice, 5(2), 5-34. https://doi.org/10.18438/B8MS6J

Santamaria, M. (2020). Concealing white supremacy through fantasies of the fibrary: Economies of affect at work. Library Trends, 68(3), 431-449.

Selman, B., \& Curnow, J. (2019). Winnipeg's Millennium Library needs solidarity, not security. Partnership: The Canadian Journal of Library and Information Practice and Research, 14(2), 1-9. https://doi.org/10.21083/partnership.v $14 \mathrm{i} 2.5421$

Shachaf, P., \& Horowitz, S. (2006). Are virtual reference services color blind? Library \& Information Science Research, 28(4), 501-520.

https://doi.org/10.1016/j.lisr.2006.08.0 09

Schlesselman-Tarango, G. (2017). How cute! Race, gender, and neutrality in libraries. Partnership: The Canadian Journal of Library and Information Practice and Research, 12(1), 1-18. 
http://dx.doi.org/10.21083/partnership. v12i1.3850

Schmidt, J. (2019). "White fragility and privilege in librarianship". Canadian Journal of Academic Librarianship. 4, 1-7. https://doi.org/10.33137/cjalrcbu.v4.32166

Summers, S., \& Buchanan, S. (2018). Public libraries as cultural hubs in disadvantaged communities: Developing and fostering cultural competencies and connections. The Library Quarterly, 88(3), 286-302. https://doi.org/10.1086/697707

Warner, J. (2001). Moving beyond Whiteness in North American academic libraries. Libri, 51(3), 167-172. https://doi.org/10.1515/LIBR.2001.167
Watson, M. (2017). “White feminism and distribution of power in academic libraries." In F. Schlesselman-Tarango (Eds.), Topographies of Whiteness: Mapping Whiteness in Library and Information Science. (pp. 143-174). Library Juice Press.

Williment, K. (2020). “It Takes a Community to Create a Library." Public Library Quarterly, 39(5), 410-420. https://doi.org/10.1080/01616846.2019 .1590757

Working Together Project. (2008). Communityled libraries toolkit. https://www.vpl.ca/sites/vpl/public/Co mmunity-Led-Libraries-Toolkit.pdf 